\title{
Online Education: A Change or an Alternative?
}

\author{
Eisam Asaqli \\ Department of Arabic Language and Literature, The Arab Academic College for Education in Israel, Haifa, Israel \\ Email: eisamasaqli@gmail.com
}

How to cite this paper: Asaqli, E. (2020). Online Education: A Change or an Alternative? Creative Education, 11, 2384-2403. https://doi.org/10.4236/ce.2020.1111175

Received: October 23, 2020

Accepted: November 22, 2020

Published: November 25, 2020

Copyright $\odot 2020$ by author(s) and Scientific Research Publishing Inc. This work is licensed under the Creative Commons Attribution-NonCommercial International License (CC BY-NC 4.0). http://creativecommons.org/licenses/by-nc/4.0/

\section{Open Access}

\begin{abstract}
Online education connects a teacher/lecturer and a student/pupil or who is not in the same physical location and not necessarily even in the same time zone. This system can operate through almost any electronic device connected to the internet. Students engaged in distance learning in real time, with teachers giving live streaming classes via the internet, are performing "synchronous learning". "Asynchronous learning" offers prerecorded classes that are always available to students. Students access these recordings when convenient for them and study and practice at their own pace. Online education has advantages, e.g., increased access to knowledge and learning and reduced teaching costs, takes less time and enables learning at one own speed, but it also has disadvantages e.g., decreasing the "market value" of an academic degree, weakening the learning quality, limiting dialogue with lecturers/teachers, and hurting academic research. Its success depends on the optimal combination of technology and pedagogy-two aspects that demand training. Regarding technology, practitioners (teachers/lecturers) must have a strong grasp of the system underlying the online courses; and regarding pedagogy, they must understand approaches for integrating technology and pedagogy, to advance innovative teaching paradigms, and promote partnership and peer learning and workshop and modular learning. The effectiveness of online education can be assessed at a number of levels: the reactions of learners when asked about their satisfaction with the learning, knowledge or ability acquisition, improvement in implementation/application, development of life skills, the degree of economic worth whileness, the relevance of the content, etc.
\end{abstract}

\section{Keywords}

Online Education, Digital Technology, Synchronous Learning, Asynchronous Learning, Professional Standards 


\section{Introduction}

From the beginning of the twentieth century, with the advent of new methods of communication, both private and mass, a novel form of learning developed. This was distance learning, learning that takes place at flexible times and geographic and physical locations near and far from each other. In the 21st century, since the global outbreak of COVID19, distance learning has become one of the major teaching methods being used by education systems around the world. Online learning or online education is a type of e-learning that utilizes the internet. Online education is one option for implementing computer-assisted learning and can also be conducted using any electronic device that enables access to the internet such as cell phones, smartphones, etc. Using online learning requires having digital literacy. Learning is done online. In other words, someone (usually a teacher or lecturer) creates content and then shares it with a group of students, who can access the content via a device connected to the internet. In addition, exams and tests can also be given and taken using online exam software. The learning material can be accessed at any time and from any place. Students do not need to be in the same physical location in order to be taught. In distance learning, the learning takes place when the teacher and the student are in two different locations, physically distant and separated, sometimes also in two (or more) different time zones. The hour when the teacher is giving the class is not necessarily the same time that the student is attending the class.

Today, students and teachers who are engaging in learning in real time generally do so using a computer. The class streams live to the students' computers. This "synchronous learning" enables a single student to have a private lesson with a teacher. Both see one another on screen, use a "virtual whiteboard" and write to each other via a chat function or talk using videoconferencing. Alternatively, group classes are also possible. Students sit in a "virtual classroom", in which they learn exactly as if they were sitting in a physical classroom. They listen to the class being taught by the teacher, and can respond to the teacher's remarks, ask questions and have discussions.

"Asynchronous learning", another distance learning method, offers learners always available prerecorded classes. Here, teachers make videotapes and upload them to a site. These comprise students' lessons, which they can access and learn at their own pace and when convenient for them. Asynchronous learning can also be performed using software programs that complement frontal teaching and that enable students to practice what they have learned in the real classroom. There is even software that gives students tests and assesses, weights and grades them.

The article is organized as follows. In Section 2, we review the historical background and early development of online education. In Section 3, we outline the advantages and disadvantages presented by online education. In Section 4, we discuss the issue of pedogeological standards for online education and in Section 5 , we examine what constitutes effective online teaching. We conclude the paper in Section 6. 


\section{Historical Background}

The attempt to develop alternatives to frontal teaching, during which the teacher/lecturer and students/listeners are physically present in the same space, is not something new. The classic format of distance learning is based on independent reading of the learning material, on performing various assignments whose purpose is to strengthen command and understanding of the material and to enable the system to test these aptitudes. Nonetheless, in parallel to the development of diverse technologies, beginning with audio- and videotapes through to the ability to transmit audiovisual content through the internet, additional models of distance learning and online learning began emerging (Goldschmidt, 2013).

Distance learning began in the nineteenth century with correspondence courses for students who did not have access to physical schools because of their geographic remoteness or certain disabilities. Beginning in the 1970s, these systems grew into computer-mediated online systems. These systems are widespread in developing countries and serve millions of pupils. Today, communication technologies, the internet and YouTube are the driving forces behind these learning systems (Moshe, 2020).

Jennifer Sumner, a researcher studying adult education, divides the history and development of distance learning into three generations:

1) Correspondence courses: This system, which developed in the nineteenth century, was based on the ability to print learning material and send it off using the postal system. Correspondence education gained great popularity and was used in primary school, middle school, academic and professional education, to the extent that even doctoral level courses were offered.

2) Distance learning: The term "correspondence education" changed to "distance learning", a broader term that was perceived as more accurately describing the expansion of teaching tools to which were added broadcast media, audio and video cassettes and to a limited degree, computers. The most widely-used application of this model was the establishment of "open universities" around the world.

3) Online-computer distance learning: This type of learning can be considered a continuation of the "one-way" system, in which interaction with the teacher or with other students is limited or does not exist at all, and it uses new technology such as the internet, modular courses, computerized questionnaires, etc. On the other hand, this approach can also be a gateway to dialogic learning, participatory learning, which is a communication activity, e.g., using videoconferencing (Sumner, 2000).

Researchers and other academics divide the history and development of online education into three generation: two primary-basic generations and a third, the next or subsequent generation:

First generation: The first generation of distance education was defined by print technology. Although one can find examples of first-generation distance 
learning going back hundreds of years, the combination of printing press technology and postal services made what is commonly known as correspondence education widely available. Driven by a strong sense of social justice, correspondence education was provided by a variety of organizations, only some of which focused on qualifications.

First-generation distance educators felt it was important to offer educational opportunities to those without easy access to education institutions. These groups often included women and working-class people, since neither group was well served by formal education institutions. The foundations of group-based adult education can also be seen during the first generation of distance education.

Second generation: The ability to broadcast using technologies such as radio and television characterized the second generation of distance education. Interaction between the teacher and the learner, or between learners, however, remained minimal. Communication was unidirectional. Providing access was seen as important and continued to be a strong driver of distance education at this time. The use of broadcast technologies is well illustrated in the development of the UK Open University (UKOU) and its use of television. Research centers, journals, conferences, and distance education-focused associations developed during this time. Early associations developed into the International Council for Distance Education (ICDE). The Commonwealth of Learning (COL) was founded in 1987. National distance organizations were also established. Academic journals emerged from the associations and distance education institutions, with most still operating today.

First- and second-generation distance teaching and learning tended to be delivered through structured material with communication dominated by the teacher. Learning was generally regarded as an individual rather than a social process. Learning models drew on cognitive or behavioral theories of learning. It was intended that the information provided in the material was there to be acquired by the student.

Subsequent generations: Nipper argued that asynchronous computer conferencing to enrich delivery defines third-generation online education. Taylor focused on the synchronous possibilities of teleconferencing (audio and video), which run counter to the flexibility offered by asynchronous distance education, and considered computer conferencing to be part of a fourth generation. Moore, drawing on the findings of Charles A. Wedermeyer's work and the practices of the UKOU, asserted that the third generation was characterized by the systemic nature of distance education. ${ }^{1}$ His fourth generation was based on the potential of teleconferencing. Despite the different terminology and areas of focus, the most common thread beyond the first two generations has been the recognition

${ }^{1}$ Charles A. Wedermeyer analyzed the teaching process, considering it to be composed of areas requiring specialist skills. He introduced the concept of team development of teaching materials. His team approach to the production and delivery of teaching material was adopted by the UKOU, where the emphasis is on high-quality courses designed for large enrolments (Wedermeyer \& Najem, 1969). 
of interaction. Interaction has subsequently remained a central focus of distance education.

Video and audio teleconferencing were used quite extensively, particularly in the United States of America. In New Zealand, the use of teleconferencing can be seen in the development of networks such as the University of Otago Audio Network.

Both audio and video conferencing extended interaction and highlighted the need to develop facilitation skills. Similarly, online computer-mediated distance education continues and extends the focus on interaction. These technologies support a move in distance education from the earlier focus on organization and didactic teaching to an emphasis on the social construction of knowledge.

Computer-mediated education has also caught the attention of face-to-face teaching institutions. It presents such institutions with possibilities for engaging with current students who seek greater flexibility in the delivery of courses, and with new cohorts of distance students.

Use of mobile technologies enables learning in places and spaces not previously conceived of as learning venues. These developments have the potential to be transformational and create new learning experiences, and to personalize the activity of learning. Some institutions confidently claim to be forging ahead and are energetically embracing these new possibilities while others are unsure. Transformation of teaching and learning requires careful exploitation of technologies, a deep understanding of teaching and learning, and expertise in the content area being delivered (Anderson \& Simpson, 2012; Burge \& Howard, 1990; Moore, 1993; Nipper, 1989; Taylor, 2001).

Some researchers claim that internet technologies and new computers that use these constitute the fourth or even the fifth generation of distance education. They point out that despite the "evolution" of learning models, the later generations of distance education did not adapt the applications of the earlier generations to other methods but only added to them new applications, and even today the traditional models of distance education are still being used (Anderson, 2011).

\section{Advantages and Disadvantages of Online Education}

\subsection{The Advantages of Online Education}

1) Increased access to knowledge and education: Elimination of the link between physical presence and participation in learning enables people in different time zones, from a range of countries around the world, to take part in academic studies. People can study at home or any other place of their choosing where they have a computer and an internet connection, at no cost or at relatively low cost compared to a university campus education. Because of these features, online education is commonly viewed as a means to increase access to knowledge and education.

2) Minimizing the cost of academic studies: Not requiring a physical cam- 
pus and its ancillary expenses, as well as the large advantage of being able to offer online courses to hundreds of thousands of students allows the cost of academic courses taught in this format to be cut. Nevertheless, to develop such a system, videotape courses, gather the associated content, prepare an exam etc. system, require a not-insignificant amount of resources. This is, however, a task that does not have to be repeated each time a new semester starts.

3) Less costly: Participants are able to learn using any device connected to the internet. There is no need to invest a lot of money in renting a place to live, pay for electricity and water, and get connected to the internet (beyond what one may pay at the moment). In addition, no travel expenses are incurred.

4) It takes less time: There is no need to waste time travelling to a physical classroom, both for the teacher/lecturer and for the students. Likewise, the teacher/lecturer does not have to repeat the same lecture to every group of students (class) taking the course (courses are often divided because of the great number of students registered). They only need to prepare the lecture once and then share it among the student groups who may not necessarily view it simultaneously.

5) Strengthening competition and developing academic education: It is anticipated that the entry of new players in the higher education market will encourage competition, in terms of the price of education, the forms the teaching will take and the range of possible pedagogical approaches. In addition, the opportunity to be exposed to the different teaching styles of teachers and to innovative technologies may enable the establishment of best practices.

6) Improved assessment of learning processes and course management: A digital learning environment enables high level knowledge and performance analysis. In principle, one can track every pause in the lecture as it is being viewed by the student as well as examine the degree of interest in and attendance of the course, give an exam immediately at the end of the lecture or at the end of a series of lectures to check if the material is being absorbed and much more. Precisely because of the great number of students, broad statistical data can be collected, which allows identification of failures in teaching or confusion or misunderstanding by many students.

7) Strengthening the link and match between academic studies and the job market: The development of online courses and the ability to match them to individual students will create a wide range of academic degrees and specialities, different than the academic degrees offered today, for which a curriculum is defined in advance, for the most part. There are those that see the ability to strengthen the link to the market and to create education systems relevant to the market as an advantage of multiparticipant online education.

8) It is modern and progressive: Most people today prefer to access content through the internet and not in other ways. This includes reading the news, watching television, talking to friends, having meetings, making purchases and the list goes on. 
9) Learning at your own pace: Students or pupils can "attend" classes at any time and from any place using their devices. Those who do not have time for frontal classes can learn through the internet whenever they have time (Dua, 2013; Goldschmidt, 2013; Harden, 2013; Kedem, Puchalla, Nelson, \& Behr, 2012; Shirky, 2012; Weller \& Anderson, 2013).

\subsection{The Disadvantages of Online Education}

1) Decrease in the "market value" of an academic degree: An academic education has many facets, among which are learning, developing intellectual curiosity and critical thinking, and attaining professional training for employment, but an academic degree is also a means to differentiate among employees, and there is concern regarding developing "inflation" among academic degrees as a result of enlarging the supply of academic studies and the ensuing drop in the value of an academic degree. On the other hand, some researchers believe that the differentiation will continue to exist and even intensify because studies on a university campus will remain the bastion of those with the means to afford such studies and those who are unable to finance their education in this way will mainly study using online courses. According to this scenario, "the market value" of non-campus-based studies will remain significantly lower than campus-based studies.

2) A deterioration in the quality of online education: The no cost model, alongside the development of a huge supply of courses, has raised concerns regarding the deterioration of the level of these courses and the development of a "Wild West", in which certificates whose source and values are not clear are being awarded. Moreover, as with the entire internet economy, the no cost model has "hidden" costs, the most prominent of which are the invasion of privacy and continual monitoring of the user's activities, mainly for marketing and publicity purposes. In addition, there is concern about not failing students who should fail because of worry about lost tuition, given that they constitute the main income stream.

3) Diminution of the dialogue with lecturers, the academic experience and the student support arrangement: Some researchers believe that while standard academic education facilitates dialogue between lecturer and student, face-to-face meeting with lecturers and researchers are absent in the MOOC (massive open online course) learning environment. According to this perspective, academic studies, at their best, constitute not only the transmission of knowledge and learning but also nurture an intellectual community and "immersion in the world of academia". The academic interaction with lecturers and with other students on campus, the time spent in the campus library and more, create a unique learning experience, whose essence is diametrically opposed to the experience generated through online learning performed in one's home.

The prevailing academic approach sees value in the interaction with not only "an effective lecturer" but also with a "leading researcher", who is conducting 
advanced research in her field. The researcher is perceived as a source of knowledge and the interaction is viewed as very important, with this significance growing the nearer one is to the source of knowledge. The move to online education may result in severing the link between research, researchers and communication and those who are mainly skilled in distance teaching.

4) Isolation: Given that participants do not have to be physically present in the classroom in order to learn, it may be difficult (or nearly impossible) to create social contacts. In addition, the feeling of being isolated and removed from the social world is negatively associated with success, and feelings of frustration because of the lack of human interaction and lack of belonging contribute negatively to intellectual and social learning development.

5) Limitations on the ability to assess students: Because of the large size of online courses, today the student assessment system is mainly based on tests and "closed" exams (multiple-choice exams), assignments and the use of textual analysis technologies, which are various softwares that enable the quality of "open" questions to be evaluated by machines. The efficiency and reliability of these tools are still being debated, and because of the importance attributed to metrics and assessment of achievements, it is one of the primary obstacles to broad assimilation of these models as alternatives to standard assessment methods used in academia today.

6) The monopolizing of the online education market by large companies: The development of online education may lead to large companies or megabrand companies taking control of the online education market. Therefore, there is concern about damage to small academic institutions, lecturers and researchers as a result of the emergence of "star lecturers" who control the market.

7) Harm to academic research: There exists the possibility of harm to academic research, some of which is funded today, among other ways, through the academic teaching system.

8) Cognitive load: Learners' coping with the online environment comprising multimedia (animation), videoclips and audio files, and the rapid shifts between the different types of media during a lesson create, at the end of the day, asides from heightened interest: a cognitive load in learners.

9) Lecturers'/teachers' inexperience: The pedagogic perception of online learning among some teachers/lecturers has not changed and, for the most part, remains the traditional one. Some teachers/lecturers do not have sufficient or rich enough experience with the teaching and active learning methods necessary for online courses.

10) Cheating: In online education, assessment methods are limited and tests are taken without students being totally supervised and hence it is easier to cheat. Accordingly, these assessment methods are not necessarily reliable (Abamu, 2018; Dua, 2013; Easy LMS, 2020a; Easy LMS, 2020b; Goldschmidt, 2013; Harden, 2013; Moshe, 2020; Shirky, 2012; Wong, Leahy, Marcus, \& Sweller, 2012). 


\section{Professional Standards for Online Teaching}

Three situations facing contemporary schools make the tasks of educational change simultaneously both fascinating and problematic. There is, first, the growing importance of educational success to individuals and societies around the world, which is triggering a corresponding need to create much more productive schools quickly. Second, the explosion of knowledge and the rapid pace of technological change suggest that what students will need to learn, and what schools might be expected to transmit, is both more complex and more difficult to codify in easily managed policy tools such as curriculum guides, textbooks, and tests. The knowledge and capacities of frontline educators, and the responsiveness of the organizations in which they work, become much more important under these conditions. Third, much of the task of preparing many more citizens for more complex kinds of learning is contingent upon dealing well with diversity, a task that twentieth century bureaucracies are ill-equipped to handle. As societies increasingly require the full range of human abilities potentially available to it, developmental strategies that build the capacities of individuals and institutions are ever more necessary (Darling-Hammond, 1998).

This complex and continually changing states of affairs in education and society have led educators and academics to try to formulate and set professional standards for the field of teaching and education. The impetus for setting such standards in the fields of teaching and education and educational policy intensified in the second half of the 1990s. The notion of educational standards was raised as part of the initiatives proposed by various governments in Australia, the US, Britain and other countries. The objective of these government initiatives was to upgrade the state of education systems and improve the actions of teachers in classrooms. In some cases, professional standards were imposed by governments on teachers as a bureaucratic way to supervise them and as a means to ensure complete professional accreditation (Sachs, 2010). In other places, the initiative to formulate standards was intended to raise professional oversight of the quality of teachers' work, as claimed by Darling-Hammond (1999). Professional standards are designed to ensure reforms in teachers' development and promotion tracks and to structure the complex work of teaching. Likewise, Darling-Hammond (1998) supports this initiative because the fundamental premise is that educational standards crystallize the foundations of knowledge in teaching and, above all, help students learn.

The main justification offered by those supporting standards is that these can create minimum requirements of professional achievements, advance teachers' professional knowledge and raise their standing. Standards define what teachers need to teach and what actions they must take to ensure that there is no drop in students' educational and learning achievements. In other words, the perception is one of quality control of the educational and learning product and its continual improvement. Another argument provided by supporters of standards is that standards can assure professional group responsibility or subordination to 
their professional circles. Namely, the education profession grants its practitioners rights, contingent on their meeting professional requirements and assuming responsibility for them. A third claim by supporters of standards who believe in quality control, in particular, Ingvarson (1998a, 1998b), is that educational standards can shape the profession of education for the long term because they bestow a long-term planning foundation in the face of continual changes in the areas of education and society. They offer the education system the stability it needs now, more so than ever.

In terms of standard setting, the International Association for K-12 Online Learning (iNACOL; rebranded in 2019 as the Aurora Institute), is at the forefront of this task. iNACOL's mission is to ensure that all students have access to a world-class education and quality online learning opportunities that prepare them for a lifetime of success. Alongside the work of the Aurora Institute, the National Standards for Quality (NSQ) online learning has been the most used and respected benchmark for states, districts, and schools aspiring to provide quality online courses, programs and teaching, since first being introduced in 2007 by the Southern Regional Education Board (SREB). The standards were revised as part of an ongoing partnership organized the Virtual Learning Leadership Alliance (VLLA) and Quality Matters (QM) that set up a committee of experts with various backgrounds in the field of K-12 online learning to take the lead in refreshing the National Standards for Quality Online Courses, Programs, and Teaching previously updated and maintained by the International Association for K-12 Online Learning (iNACOL) (NSQ, 2020). The NSQ are designed to provide states/countries, districts, online programs, and other organizations with a set of quality guidelines for online teaching. The standards as identified by SREB are already in use by sixteen SREB states. They proved to be the most comprehensive among those reviewed and include guidelines set forth in the other criteria drawn from the literature review.

The following are examples of standards of the NSQ Online Teaching (iNACOL, 2011: pp. 2-16):

- The online teacher knows and understands critical digital literacies and 21st century skills.

- The online teacher knows and understands appropriate use of technologies to enhance learning.

- The online teacher knows the primary concepts and structures of effective online instruction and is able to create learning experiences to enable student success.

- The online teacher is able to apply current best practices and strategies in online teaching to create rich and meaningful experiences for students.

- The online teacher is able to build learner capacity for collaboration in face-to-face, blended, and online environments and encourages students to participate as global citizens.

- The online teacher is able to select and use a variety of online tools for communication, productivity, collaboration, analysis, presentation, research, and 
online content delivery as appropriate to the content area and student needs.

- The online teacher is able to effectively use and incorporate subject-specific and developmentally appropriate technologies, tools, and resources.

- The online teacher is able to use communication technologies in a variety of media and contexts for teaching and learning.

- The online teacher is able to use student-centered instructional strategies that are connected to real-world applications to engage students in learning (e.g., peer-based learning, inquiry-based activities, collaborative learning, discussion groups, self-directed learning, case studies, small group work, and guided design).

- The online teacher is able to use differentiated strategies in conveying ideas and information, and is able to assist students in assimilating information to gain understanding and knowledge.

- The online teacher is able to apply strategies for engagement in online learning environments, e.g., asking questions to stimulate discussion.

- The online teacher is able to provide a variety of ongoing and frequent teacher-student interaction, student-student interaction, and teacher-parent interaction, and teacher-mentor interaction opportunities.

- The online teacher is able to provide prompt feedback, communicate high expectations, and respect diverse talents and learning styles.

- The online teacher is able to provide clear definitions of objectives, concepts, and learning outcomes and course organization to students.

- The online teacher is able to establish standards for student behavior that are designed to ensure academic integrity and appropriate use of the internet and online written communication.

- The online teacher is able to monitor student progress and apply activities and tools that are relevant to the needs of all students, including those with learning or physical disabilities, in collaboration with appropriate staff or resources.

- The online teacher is able to apply adaptive and assistive technologies in the online classroom where appropriate in the instruction to meet student needs.

- The online teacher is able to create and implement assessments in online learning environments in ways that ensure validity and reliability of the instruments and procedures.

- The online teacher is able to develop and deliver assessments, projects, and assignments that meet standards-based learning goals and assess learning progress by measuring student achievement of learning goals.

- The online teacher is able to modify and add content and assessment, using an online Learning Management System (LMS).

- The online teacher is able to create and modify engaging content and appropriate assessments in an online environment.

- The online teacher is able to incorporate multimedia and visual resources into an online module. 
Recently, the ministries of education of many countries have been leading an innovative program called "Adapting the Education System to the 21st Century". At its core, the program seeks to assimilate multi-resource innovative technologies in schools. This objective is to be realized through adapting curricula and training teaching staff that will give students the learning skills required by citizens of the modern technological era. The people working on the program development internalized the lessons from early information and communication technology programs and built a sophisticated assimilation system, which they claim, will initiate the sought-after change in the education system. In their mind, assimilation of the innovative technologies in the education system is unavoidable because, today, a modern education system cannot exist without massive integration of technologies for learning and teaching. Nevertheless, this integration requires that decision makers operationalize a broad system of deep deliberation, without which the assimilation is likely to fail (Eshet, 2013).

Some educators and academics define the standards as a consequence of the integration of technology in learning processes. They are seeking the correct way to integrate the technology and exploit the opportunities it offers in the learning environment. They see that the success of online learning is contingent on the optimal integration of technology with pedagogy. Both features require training. Regarding technology, practitioners must have deep knowledge of the system in which the online courses are embedded. Regarding pedagogy, it is essential to expose teacher/lecturers to ways of integrating technology and pedagogy, in order to promote new teaching paradigms. Advancement of collectivity and peer learning, authentic and problem-focused learning and workshop and modular learning-all constitute a challenge for the lecturer of an online course and a means to empower the learning (Baruch, 2009). In addition, research (see, e.g., Henrickson \& Doerig, 2013) has proven that the pedagogical combination of experiential learning and e-learning environments intensifies learners' enjoyment of the learning and the positive involvement in the learning process and heightens their curiosity significantly. One well-known model relates to the pedagogical use made by a course website developed by the Harasim, Hilts, Teles and Turoff (1995). According to this model, the online learning interface can be used in one of three ways:

- Adjunct mode: Use of the web to empower traditional teaching in face-to-face courses and their enrichment, and not as a required component, which is graded. Use of the website may be a formal requirement made by the lecturer, or an optional one encouraged by the lecturer, to exploit existing resources-whether these are unidirectional (papers, professional material), interactive (instant messages, chats, discussion group forums) or managerial (announcements, tests, sending of assignment to submission boxes etc.). These types of usage are the most common in institutions of higher education, in general, including teacher training colleges.

- Mixed mode: The main feature here is that the use of the course website comprises a significant part of the teaching and learning process. Using the 
web is mandatory and constitutes a part of the course grade. In some cases, the lecturer converts some of the face-to-face meetings into online meetings. Therefore, the presence of the lecturer and the students on the website is very high, as is their active participation in the learning.

- Online mode: The course website and the internet are the only teaching and learning environments in the course, both as resources and as areas for synchronous and asynchronous activities.

Shana Kirk (2019) tried to formulate professional standards for online distance learning. She believes that the more widespread distance education becomes, the more teachers must try to find additional ways to create an effective learning environment for students. Therefore, it is imperative to ensure that online teaching practices meet the same standards as classroom meetings and allow students to concentrate in the best possible way. To this end, as a preparatory stage before even beginning the class, she recommends that teachers must see to the following:

- Avoid disarray or too much decoration in the background of the teaching area.

- Ensure that the lighting is good.

- Keep pets and children outside of the frame.

- Silence background noises.

Further, Kirks says that the technical quality of the computer and microphone has a critical impact on the level of students' attention. Therefore, teachers must ensure that they are connected to fast internet, that not too many tabs are open on their browser, that they are using a convenient and appropriate video chat platform (e.g., Skype, Zoom, FaceTime), and that students see them as clearly as possible, even via two cameras, if the option exists.

She also notes that time organization is inseparable from quality online teaching. To make sure all the teaching material is reviewed, to connect to their listeners, to engage them and maintain their energy, teachers must do the following:

- Prepare, in advance, time-limited lesson plans.

- Take into consideration that the first five minutes will be wasted by technical issues such as connection problems, hearing problems, camera problems.

- Have a plan B ready: If, for instance, the internet fails or some participants get disconnected suddenly, bring out an exercise prepared ahead of time, conduct a short review of material or use the time to answer students' questions.

Expectations from students: Truthfully, you cannot expect students' rooms, where they are learning, to be neat. Nevertheless, it is the teachers' responsibility to ascertain that the students come to the class prepared, by doing the following:

- Send students a list of items that they must bring to the lesson.

- Make it clear that there are rules of etiquette in online classes: Students are to see to eat, drink, use the washroom or take the dog for a walk before or after class. 
- Request that the student's room not have any distractions in it such as computer games, videos, a television and family members entering and leaving.

Georgia Institute of Technology graduate students completed surveys and feedback questionnaires about online classes they attended over eight semesters. Using the data provided by them about the effectiveness of the online classes, seven principles and standards for designing and developing education video classes were drawn up (Ou et al., 2019):

1) Teaching using examples: Effective teaching occurs when students absorb knowledge using concrete aids. Therefore, online teaching must include living and experiential examples that build and shape in the best way the knowledge that students are absorbing.

2) Teaching by getting students to act: Many studies have shown that effective learning heightens and leads to achievements. Even though and because students are not sitting physically in front of the teacher, the teacher must motivate them to action and engage them.

3) Give feedback immediately: Practicing or exercising without getting feedback does not help student learn and improve. Within the classroom, students usually get feedback immediately, positive or negative, on any of their answers to questions and may even get a second chance to answer if their first try was erroneous. In online classes, however, it is very difficult to answer a student immediately. Therefore, teachers must try to create an algorithm for automatic feedback that immediately responds by verifying the students' answers or referring them to relevant information. The amount of time allocated to giving a response can be set in advance.

4) Teaching through reflection: Teachers must allow students to undergo a process of reflective learning in order for them to absorb the material properly. For example, students could write in a notebook, keep a diary, give themselves feedback, conduct peer assessment and read papers.

5) Personalization: The appearance of a sociable figure on the screen may motivate the students to participate and take an interest. Therefore, teachers should:

- Use a conversational tone, instead of an authoritative one.

- Relate to students and allow them to express themselves.

- Be visible, present themselves and even consider including other speakers in their lectures.

6) Multimedia: Leading online classroom lecturers, e.g., lecturers from the Khan Academy, tend to use traditional techniques and gestures, such as writing on a whiteboard, to create a natural feeling of a teacher in a classroom, give students time to absorb the material and reduce the cognitive load of watching video classes. Hence, it is recommended to increase the use of visual information, such as graphs, tables and illustrations; students assimilate material better when it is presented to them visually.

7) Creating a continuum: In general, teaching a course must include a series of topics, ideas and theories that move along a defined linear axis. Against this 
background, teachers should try to connect problems, examples, rules and practices presented to students. Confusion or interrupting the learning track may lead to different learning outcomes among students.

The findings of other studies demonstrate that the clear majority of students expect the personal presence and emotional involvement of the lecturers/teachers in the online course. Students expect the lecturer teaching a course to show a more personal attitude, demonstrate sensitivity, be open, be humorous and relate in a personal manner to the students using individual feedback (see, for example, Cleveland-Innes \& Campbell, 2012).

Researchers and other academics such as Ulf-Daniel Ehlers (2006) emphasize the importance of not viewing quality development as an add-on to online learning, e.g., as an isolated evaluation approach at the end of a course. Quality development is viewed as a key aspect of the learning, occurring in every single development and delivery process of e-learning courses and programs. From the above literature review, we can see that three main concepts emerge can be combined to form a new, comprehensive perception of quality development: 1) Quality development leads to better learning. This perspective can be called education-orientated quality development; it emphasizes that quality development has to take into account the learners' situation. Learners' preferences are analyzed to show that they cover a multitude of factors and preference profiles. This suggests that quality approaches have to be highly flexible and allow for individualized quality. 2) Quality development, further, has to take into account not only learners' needs; it is a process in which the interests and requirements of the e-learning stakeholders have to be considered as a whole and combined to form a comprehensive concept. Quality in this respect is seen as a relationship between the demands and needs of a stakeholder group and the actual delivery of online education. To shape this relationship in the best possible way, a negotiation process is necessary, involving all stakeholders and integrating their preferences and situations against the background of the given economic and organizational situation. These negotiation processes occur in different positions of the learning environment. Ehlers suggest utilizing process models such as the ISO Reference Model. 3) The third part of the concept is concerned with the question of how existing concepts, approaches and strategies can be used for quality development. Ehlers proposed a decision cycle that makes it possible to find a suitable quality approach for a given context. To decide which quality approach is suitable, to choose from a set of possible strategies, and to adapt those strategies to the specific situational context, certain competencies are necessary. To acquire these competencies, Ehlers developed the concept of quality literacy. It covers competencies such as knowledge of quality development, experiences in using particular instruments, modification skills and the ability to thoroughly analyze one's own situation and needs.

\section{Effectiveness of Online Teaching}

Other researchers, among them Kirkpatrick and Kirkpatrick (2016), expanding 
on the original four levels of training evaluation, tried to map and measure the effectiveness of different levels and aspects of online learning:

- Effectiveness at the level of reaction: What are the reactions of learners regarding satisfaction with the learning, the location where they learn, the degree of participation, the level of enjoyment from the learning and efficient use of time? Here, the satisfaction of teachers with their students, of parents, of principals and of supervisors responsible for the learning being performed is also measured. Self-reporting of satisfaction (Do students like it?) is one significant metric of the degree of effectiveness.

- Effectiveness at the level of learning: Acquisition of knowledge or ability, the scope of advancement in performance or of students following the learning are evidence of the results of the students' learning. Researchers also include in this level specific populations of organizations and institutions of higher learning whose achievements are ranked through comparative tests such as PISA (Program for International Student Assessment).

- Effectiveness at the level of behavior: Improvement of the ability to perform/implement. Here the degree to which the level of the learner's behavior during performance of an assignment, following the learning, has changed. Has the learner validated the learning? Does she demonstrate relevant skills and knowledge as she carries out the assignment? And is he able to extrapolate from what he has learned to other situations or transfer this knowledge to his peers? In other words, "knowledge transference" is being measured here.

- Effectiveness at the level of results: Has there been an impact on the organization's or environment's performance on the level of performance in measurable terms? Researchers have included in the results level the acquisition of life skills, degree of continuity and the use of life skills in getting into the job market, the level of command of effective communication skills essential for online learning and lifelong learning as well as the speed of implementation of the required knowledge or skills (Bowyer \& Chambers, 2017; Kirkpatrick \& Kirkpatrick, 2016; Hecht, 2018).

- Cost-effectiveness of e-learning technology: The level of economic feasibility (return on investment-ROI) of the investment in software, educating, and maintenance on the national, institutional, organizational and even course-specific levels (Roxana, 2017; Watershed Insights, 2017).

- The dropout rate in massive online courses (MOOC): These courses have indeed gained a reputation for success among academics because of the impressive registration numbers; however, the high dropout rates and the low completion rates testify to their failure (Downey, 2016; Kolowick, 2013).

- Assessment quality: Assessment is done according to the objective-oriented assessment of Quality Matters, which assumes that each person has a unique learning experience and that each target audience has a different interpretation of the significance of the words "quality", "value", and "worth" (Youger \& Ahern, 2015). 
- Relevance of the content: Most content taught at the primary, high school and post-secondary school levels has changed very little. Many institutions that are supposed to be the nexus of innovation and revolution are still mired in the past (Ben David, 2018; Elliott, 2017).

\section{Conclusion}

Online education rests on the integration of digital technology in teaching and learning, and it constitutes a potential for significant change in the area. Today, it is still developing and there is a chance that in the future it will comprise an alternative to traditional education. Accordingly, learners who are unable to assimilate into the complex digital-technological space will also be unable to participate fully in the learning, academic, social and cultural milieu surrounding them. Online pedagogy can help these people. In parallel, there still exists the phenomenon among teachers and lecturers around the world that seek to preserve the traditional learning culture. Many teachers and lecturers continue to teach the way they have always taught, without trying and using alternative ways to learn. They believe that their educational culture and values are being threatened and their guarding these is preventing the dismantlement of the existing education and learning system, as well as the national education system.

To date, many studies have indicated that despite the assimilation of new and varied technology in schools and academic, the teaching and learning culture, in a significant number of these institutions, has not changed and remains traditional, which is a direct result of the fear of online learning. The main obstacle to its development stems from the continued integration of nonhuman technologies such as artificial intelligence devices and robot teachers that heighten the post-humanist experience and decrease the sense of humanity, which makes it essential for teachers/lecturers to display a personal attitude, sensitivity, and openness, express humor and relate to learners individually by giving personal feedback.

In the meantime, the education and learning system is at a crossroad: either online learning triggers a change in the system or it becomes an alternative to it. We will have to wait a number of years to see which road the education system goes down in the future.

\section{Conflicts of Interest}

The author declares no conflicts of interest regarding the publication of this paper.

\section{References}

Abamu, J. (2018). The Number of Students Taking Online Courses Is Quickly Rising, but Perceptions Are Changing Slowly. Edsurge. https://www.edsurge.com/news/2018-06-12-the-number-of-students-taking-in-onlinecourses-is-quickly-rising-but-perceptions-are-changing-slowly

Anderson, B., \& Simpson, M. (2012). History and Heritage in Open, Flexible and Dis- 
tance Education. Journal of Open, Flexible, and Distance Learning, 16(2), 1-10.

Anderson, T. (2011). Three Generations of Distance Education Pedagogy. International Review of Research in Open and Distance Learning, 12, 80-97.

https://doi.org/10.19173/irrodl.v12i3.890

Baruch, A. (2009). Quality Online Learning. (In Hebrew)

https://portal.macam.ac.il/article/\%D7\%9C\%D7\%9E\%D7\%99\%D7\%93\%D7\%94-\%D7 \%9E\%D7\%A7\%D7\%95\%D7\%95\%D7\%A0\%D7\%AA-\%D7\%90\%D7\%99\%D7\%9B\%D7 \%95\%D7\%AA\%D7\%99\%D7\%AA/

Ben David, Y. (2018). The Problem with University. Ha'aretz. (In Hebrew) https://www.haaretz.co.il/blogs/midatova/BLOG-1.5869004

Bowyer, J., \& Chambers, L. (2017). Evaluating Blended Learning: Bringing the Elements Together. Cambridge Assessment: Research Matters, 23, 17-26.

Burge, E. J., \& Howard, J. L. (1990). Audio-Conferencing in Graduate Education: A Case Study. American Journal of Distance Education, 4, 3-13.

https://doi.org/10.1080/08923649009526699

Cleveland-Innes, M., \& Campbell, P. (2012). Emotional Presence, Learning, and the Online Learning Environment. International Review of Research in Open \& Distance Learning, 13, 269-292. https://doi.org/10.19173/irrodl.v13i4.1234

Darling-Hammond, L. (1998). Policy and Change: Getting Beyond Bureaucracy. In A. Hargreaves, A. Lieberman, M. Full, \& D. Hopkins (Eds.), International Handbook of Educational Change (pp. 642-667). Dordrecht: Springer.

https://doi.org/10.1007/978-94-011-4944-0 32

Darling-Hammond, L. (1999). Reshaping Teaching Policy, Preparation and Practice: Influences on the National Board for Teaching Professional Standards. Washington, DC: AACTE Publications.

Downey, M. (2016). Online Courses Explode, But 90 Percent of Enrollees Drop Out Within Two Weeks. Why? AJC.

https://www.ajc.com/blog/get-schooled/online-courses-explode-but-percent-enrolleesdrop-out-within-two-weeks-why/wEGL45m6fM2SQnvQS5g6XN/

Dua, A. (2013). College for All. McKinsey \& Company. https://www.mckinsey.com/industries/public-and-social-sector/our-insights/college-fo $\underline{\mathrm{r} \text {-all }}$

Easy LMS (2020a). Advantages and Disadvantages of Online Learning. (In Hebrew) https://www.easy-lms.com/he/knowledge-center/lms-knowledge-center/advantages-an d-disadvantages-of-online-learning/item 12529

Easy LMS (2020b). Online Learning versus Classic Learning. (In Hebrew) https://www.easy-lms.com/he/lms-knowledge-center/online-learning-vs-traditional-lea $\underline{\text { rning/item } 12530}$

Ehlers, U. (2006). Towards Greater Quality Literacy in an eLearning Europe. eLearning Papers.

https://pdfs.semanticscholar.org/5865/4e263d859a8aa487a42a3169c762aa69a75e.pdf

Elliott, L. (2017). Heretics Welcome! Economics Needs a New Reformation. The Guardian.

https://www.theguardian.com/business/2017/dec/17/heretics-welcome-economics-nee ds-a-new-reformation

Eshet, Y. (2013). Integrating Technology into Education: How to Do It Correctly? Calcalist. (In Hebrew) https://www.calcalist.co.il/local/articles/0,7340,L-3596160,00.html

Goldschmidt, R. (2013). Online Academic Learning and Recognition of It. Jerusalem: The 
Knesset, Center for Research and Information. (In Hebrew)

Harasim, L., Hiltz, S. R., Teles, L., \& Turoff, M. (1995). Learning Networks: A Field Guide to Teaching and Learning Online. Cambridge, MA: MIT Press.

Harden, N. (2013). The End of the University as We Know It. The American Interest. https://web.archive.org/web/20131104162320/http://the-american-interest.com/article. $\underline{\mathrm{cfm}}$ ?piece $=1352$

Hecht, Y. (2018). About the Effectiveness of Online Pedagogy. Israel Internet Association. (In Hebrew)

https://www.isoc.org.il/internet-il/articles-and-research/magazine/the-effectiveness-ofonline-pedagogy

Henrickson, J., \& Doering, A. (2013). Adventure Learning and Learner-Engagement: Frameworks for Designers and Educators. Journal of Interactive Learning Research, 24, 397-424.

Ingvarson, L. (1998a). Professional Standards: A Challenge for AATE. English in Australia, 122, 31-44.

Ingvarson, L. (1998b). A Professional Development System Fit for a Profession. Semantic Scholar.

https://www.semanticscholar.org/paper/A-professional-development-system-fit-for-a-I ngvarson/779bb194adfdc0289a0b1f4f512641a77ae6aaf1

International Association for K-12 Online Learning (iNACOL) (2011). National Standards for Quality Online Teaching (Version 2). Vienna: iNACOL.

Kedem, K., Puchalla, J. E., Nelson, J. C., \& Behr, E. (2012). Shifting Ground: Technology Begins to Alter Centuries-Old Business Model for Universities. Moody's Investors Service.

https://www.etsu.edu/125/taskforces/programs and opportunities/documents/mooc.p df

Kirk, S. (2019). Excellence Online: Professional Teaching Standards for Distance Learning. American Music Teacher, 68, 14-17.

Kirkpatrick, J. D., \& Kirkpatrick, W. K. (2016). Kirkpatrick's Four Levels of Training Evaluation. Alexandria, VA: ATD Press.

Kolowick, S. (2013). Coursera Takes a Nuanced View of MOOC Dropout Rates. University of Pittsburgh Coursera Users.

https://pittcoursera.wordpress.com/2013/04/08/coursera-takes-a-nuanced-view-of-mo oc-dropout-rates/

Moore, M. G. (1993). Theory of Transactional Distance. In D. Keegan (Ed.), Theoretical Principles of Distance Education (pp. 22-29). New York: Routledge.

Moshe, M. (2020). Learning from a Distance But Feeling Close. (In Hebrew) https://www.maimonmoshe.com/blank-32

Nipper, S. (1989). Third Generation Distance Learning and Computer Conferencing. In R. Mason, \& A. Kaye (Eds.), Mindweave: Communication, Computers and Distance Education (pp. 63-73). Oxford: Pergamon Press.

NSQ (2020). National Standards for Quality. https://www.nsqol.org/about/

Ou, C. H., Joyner, D. A., \& Goel, A. K. (2019). Designing and Developing Video Lessons for Online Learning: A Seven Principle Model. Online Learning, 23, 82-104. https://doi.org/10.24059/olj.v23i2.1449

Roxana, M. (2017). Why It's Important to Calculate the ROI of Training in Order to Ensure the L\&D Budget. Matrix Blog.

https://blog.matrixlms.com/author/roxana-mitu/page/2/ 
Sachs, J. (2010). Teacher Professional Standards: Controlling or Developing Teaching? Teachers and Teaching: Theory and Practice, 9, 175-186.

https://doi.org/10.1080/13540600309373

Shirky, C. (2012). Napster, Udacity, and the Academy. Clay Shirky's Blog. https:/pages.uoregon.edu/ucouncil/documents/resources/2012-2013/02.11.13 Shirky.c om \%20Napster,\%20Udacity\%20\&\%20the\%20Academy\%20(C.\%20Shirky).pdf

Sumner, J. (2000). Serving the System: A Critical History of Distance Education. Open Learning, 15, 267-285. https://doi.org/10.1080/713688409

Taylor, J. C. (2001). Fifth Generation Distance Education. Higher Education Series. http://www.c3l.uni-oldenburg.de/cde/media/readings/taylor01.pdf

Watershed (2017). An Overview: Phillips' Model for Learning Evaluation. Watershed. https://www.watershedlrs.com/blog/learning-evaluation/phillips-model/

Wedermeyer, C. A., \& Najem, R. E. (1969). AIM - From Concept to Reality: The Articulated Instructional Media Program at Wisconsin. Syracuse, NY: Syracuse University Publications in Continuing Education.

Weller, M., \& Anderson, T. (2013). Digital Resilience in Higher Education. European Journal of Open, Distance and e-Learning, 16, 53-66.

Wong, A., Leahy, W., Marcus, N., \& Sweller, J. (2012). Cognitive Load Theory, the Transient Information Effect and e-Learning. Learning and Instruction, 22, 449-457.

https://doi.org/10.1016/j.learninstruc.2012.05.004

Youger, R. E., \& Ahern, T. C. (2015). Is a Quality Course a Worthy Course? Designing for Value and Worth in Online Courses. Online Journal of Distance Learning Administration, 18, 1-9.

https://www.westga.edu/ distance/ojdla/spring181/youger ahern181.html 